\title{
Commentary
}

\section{Enablers for Achieving a Pathway to Sustainable Development in Sierra Leone}

\author{
Ishmail Sheriff ${ }^{1, ~ *, ~ S i s a y ~ A b e b e ~ D e b e l a ~}{ }^{2}$, Matthew James Turay ${ }^{3}$, Osman Alhaji Kabia ${ }^{4}$, \\ Musa Titus Sesay ${ }^{1}$ \\ ${ }^{1}$ School of Environmental Science and Engineering, Suzhou University of Science and Technology, Shihu Campus, Suzhou; People's \\ Republic of China \\ ${ }^{2}$ School of Public and Environmental Health, Hawassa University College of Medicine and Health Science, Hawassa; Ethiopia \\ ${ }^{3}$ School of Economics, Beijing Technology and Business University, People's Republic of China \\ ${ }^{4}$ Department of Geography and Rural Development, Faculty of Social Sciences, Ernest Bai Koroma University of Science and Technology, \\ Makeni Campus, Sierra Leone
}

\section{Email address:}

s.ishmail@rocketmail.com (I. Sheriff),sisaya@yahoo.com (S. A. Debela), matthewjamesturay@yahoo.com (M. J. Turay), kosmanalhaji@gmail.com (O.A. Kabia), sesaymusatitus@gmail.com (M. T. Sesay)

${ }^{*}$ Corresponding author

\section{To cite this article:}

Ishmail Sheriff, Sisay Abebe Debela, Matthew James Turay, Osman Alhaji Kabia, Musa Titus Sesay. Enablers for Achieving a Pathway to Sustainable Development in Sierra Leone. International Journal of Sustainable Development Research. Vol. 6, No. 2, 2020 , pp. $30-36$. doi: $10.11648 /$ j.ijsdr.20200602.12

Received: April 8, 2020; Accepted: May 3, 2020; Published: May 28, 2020

\begin{abstract}
It is almost five years since the adoption of the United Nations (UN) sustainable development agenda and its Sustainable Development Goals (SDGs) by the United Nations General Assembly (UNGA) in 2015. While each member state has the flexibility to design its own SDGs priorities, and is on the implementation process of the goals, here, we suggest how better planning, research, and innovation could help to achieve sustainable development in Sierra Leone. We draw attention to the necessity of developing a national sustainable development plan in Sierra Leone to guarantee concentrated national priorities so as to strengthen the efficiency of interventions and to effectively deliver sustainable development outcome. However, this will require the commitment of political parties, and other stakeholders so as to prevent a predisposition to create intergenerational and intragenerational imbalances. As enablers for the achievement of sustainable development, investment in and support for research and development is a crucial architecture that is required to implement, monitor and evaluate performance, and track progress on the SDGs, and also identify challenges so that they can be adequately addressed. While Sierra Leone has aspired to become an innovation hub in Africa, central to the success of such a dream and aspiration is the enactment of a resolution that can ensure the sustainability of the Directorate of Science Technology and Innovation (DSTI) which is the country's innovation platform in future government administrations.
\end{abstract}

Keywords: Sierra Leone, Sustainable Development Goals, Innovation, Research and Development

\section{Introduction}

In September 2015, the United Nations General Assembly (UNGA) adopted the 2030 Agenda for Sustainable Development including the 17 Sustainable Development Goals (SDGs) [1-2]. The post-2015 development framework is seen as a sign of international concerted efforts and commitment, focused on advancing social inclusion, environmental protection and, economic growth; in a mutually reinforcing manner [1, 3-4]. This comprehensive agenda serves not only as an important policy instrument for international development cooperation but also as a national development mechanism of all United Nations (UN) member states from 2016 - 2030. Albeit, it has a greater scope, considering its contents and actions than its predecessor [5-6] - the Millennium Development Goals (MDGs) - it opens a 
new front of multifaceted challenges, especially in the nationalization processes and implementation phase at country level.

The applicability and priority of individual SDGs, considering different national realities, vary across member states. In recognition of this variability, the formulation of national indicators, selection of targets, and development of priorities was and would continue to be the ultimate role of individual countries [7]. While Member states are applying the lessons learned from the MDGs' framework weakness and implementation challenges, the High-Level Political Forum (HLPF) on sustainable development, has been conducting thematic and regular reviews based on Voluntary National Reviews (VNRs). This is done to closely follow up on progress made on the SDGs, coupled with the fact that the means to bring nations into account for their commitments under international bound conventions are generally weak [8-9]. As such, twenty-two (22) UN member states including the Republic of Sierra Leone prepared and presented their first VNRs at the 2016 HLPF [10]. Sierra Leone's VNR described the nationalization and implementation process of the 2030 agenda, and also highlighted the SDGs baselines, targets, and indicators used to measure progress towards them; considering the specific circumstances and context of the country [11]. While the country did not participate in the 2017 and 2018 VNRs, the Government of Sierra Leone had presented its second VNRs at the recently held HLPF in July 2019 [12].

It is now almost five years since the adoption of the SDGs. In an influential set of annual reports, the UN had asserted that taken as a whole, the pace of progress on the SDGs is uneven and sluggish [13-15]. The question of the gravity of inadequacy of progress being made on the SDGs targets, and indicators is, however beyond the scope of discussion on this paper. Here, the overarching objectives of this piece were to (1) elucidate the importance of better national planning for the SDGs in Sierra Leone (2) highlight how investment in research and innovation can be used as an impactful mechanism in spurring up the successful implementation of the SDGs in Sierra Leone.

\section{The Need for a Long-term National Plan for Implementing the SDGs in Sierra Leone}

Few countries have a clear idea of the global meaning of the SDGs at the national level, or if the achievement of the goals within the stipulated timeframe is possible and if so, how [16]. In this sense, it is important to note that the UN agenda on sustainable development presents new areas of opportunity for every member state. In Sierra Leone, tapping into the opportunities embedded in the SDGs, however, will require policy coherence, and a long-term national sustainable development plan (dubbed as a vision in this present context). Such a plan is necessary to ensure that there is concentrated national priorities, and that the SDGs are properly contextualized to address national realities. It could help to prevent a predisposition to create intergenerational and intragenerational imbalances. In fact, literature acknowledges that translating the global SDGs into a national context requires a clear, long-term vision [3]. Put another way, the achievement of the SDGs is hooked on the willingness of national governments taking ownership and marshaling out policies, plans and programs [5]. However, the notion of a long-term national plan or vision for the SDGs is seemingly an impossible theorem in Sierra Leone if the current pattern of national planning is not changed. In order to place our argument in context, it is necessary to understand the history of long-term national plans (national visions) for Sierra Leone.

For instance, Vision 2025 was launched on $15^{\text {th }}$ March 2001, followed by Vision 2025 document on $12^{\text {th }}$ December 2003 [17]. This vision called for a "United People, Progressive Nation, and Attractive Country". Further, the idea of a national vision for Sierra Leone was also enshrined in chapter eight (8) of the Sierra Leone Truth and Reconciliation Commission (TRC) report volume three B [18]. However, Vision 2025 was discontinued by the recent past government (2007-2018), which in 2012 promulgated Sierra Leone's Third Poverty Reduction Strategy Paper (PRSP III) which became known as the Agenda for Prosperity (AFP) (2013-2018) [19]. This national agenda highlighted a vision for Sierra Leone to become an inclusive, green, middle-income country by 2035 . The AFP/PRSP III was said to be the first five years road map towards that aspiration. The implementation of the Agenda for Prosperity and its vision 2035 had been heavily criticized by the current government $(2018$ - 2023), which had recently launched its medium-term national development plan entitled "Education for Development" (2019-2023) [20]. The plan outlined national priorities as well as implementation strategies in the form of different policy packages. Further, the document is said to be rooted in a twenty years comprehensive national development plan (dubbed vision 2039) but does not outline technical specificities.

It is highly likely that the current discussions on vision 2039 by the present administration would later be dismissed as a folly and a waste of efforts by a successive government, especially one that will emerge from an opposition political party or a coalition of opposition political parties. This pattern of discontinuity of national visions by previous and current national governments is a dangerous sign of attaining the SDGs and is a counter-transformation in a sustainable development context. If the current pattern of national planning remains unchecked, it will fickle much of the implementation process of the SDGs and thus, jeopardize their achievement. Add to this, it may consequently create a dilemma of deciding on what is to be developed and what is to be sustained by 2030 and beyond. Indeed, as Kickbusch \& Hanefeld [5] argued, the political reality of each country which includes development agendas, political systems, and ideologies - will have an impact [either positive or negative] on the achievement of the SDGs at a local level.

On the basis of the above-mentioned narratives, there is a 
particularly urgent need for a standardized national sustainable development plan or vision which will need to include an extensive list of national priorities, detailed programs, and specific activities; which is periodically reviewed and updated, based on their progress, targets, and timelines for their achievement and with a clear thematic actors and responsibility at its core. Once such a national plan or vision for the SDGs is operationalized, it may be a sure guarantee to transition Sierra Leone to a sustainable development pathway. Short- and medium-term national development plans of future governments could also be developed from this national sustainable development vision, so as to ensure a consistent sustainable development path.

\section{The Interplay of Political Nexus and Societal Cohorts in Forming a National Sustainable Development Vision}

The SDGs process acknowledged the need for a more consultative process, considering the interdisciplinary and multidimensional nature of sustainability issues [21]. Taking into account the current political landscape of Sierra Leone, the basic guidelines on the framework and design of a national sustainable development plan or vision for Sierra Leone would necessarily require an extensive all-partisan approach to its formulation. It is important to note that the political process through which the plan or vision is developed is a key in building consensus around a common vision, and this could be manifested by a strong representation from different political cohorts. More attention will be required in the areas of defining the roles of political parties in implementing a vision and set of clear rules for enforcing a vision for the SDGs. Engebretsen et al., [9] point out that the implementation of the 2030 agenda requires strong commitment and accountability. Therefore, as a show of commitment, it will be necessary, for all [operational] political parties to sign a communiqué in support of a national vision for the SDGs. This is of great importance in order to galvanize further and substantial political commitment and cooperation, since a national vision for the SDGs will be part of the policy frameworks of many future governments. In addition, to guarantee the longevity of a national sustainable development plan or vision over time, it will be necessary to have strong backing by the Sierra Leone House of Parliament. This could serve as a protective measure against the tendency for a future government to discontinue its implementation, as it has always been the case with previous national visions.

Sustainable development, being a form of societal change requires active participation by competent people [22]. Academia is a key sector of society that must be greatly involved [not only on a mere consultation basis] in the process of developing and implementing a national plan or vision for the SDGs. This is because academics and researchers can take on a role as change agents for societal transformation at the interface between scientific, political, and societal stakeholders and institutions [23]. Academics are well poised to work with policy-makers and other stakeholders to develop new metrics, identify public policy priorities, evaluate and assess policies [24]. Additionally, they can work to ensure the cultural, socio-economic and policy dimensions of the SDGs are fully integrated into a long-term national sustainable development plan in a coherent and balanced manner.

The 2030 development agenda on sustainable development is more collaborative and inclusive and does not tolerate the repetition of previous bureaucratic issues registered under the MDGs [25]. Thus, achieving the SDGs will demand everyone from every meaningful sector to contribute to its implementation [26]. Whatever shape a national sustainable development vision takes, it is vital that special efforts are made to take account of the common national hopes and aspiration, and the voices of poor and marginalized groups, Civil Society Organizations (CSOs) and other stakeholders. This approach is critical to ensure the outcome better reflects the key principle of leaving no one behind as documented in the UN sustainable development agenda. Given the level of development and governance architecture in Sierra Leone, the SDGs have provided the opportunity to change dramatically, for the better or worse the country's development trajectory.

\section{Support for Research and Innovation as Drivers of Implementing the SDGs}

Research and Innovation is increasingly seen as an essential tool underpinning activity in all spheres of development - ranging from economic sectors, through to social and environmental spheres. It is important to mention here that there is no independent SDG on research and innovation but these are explicitly recognized in a number of the SDGs, their indicators and targets [26]. Having this in view, the role of research and innovation in implementing and monitoring the SDGs was discussed at a UN multi-stakeholder forum on Science, Technology and Innovation (STI) held in New York in June 2016 [27] and has been well documented [28-29].

It has been reported that the SDGs are seen as an opportunity to stir up sustainability research, as the current research pace and progress have not halt humanity from overstepping its planetary boundaries [30]. To address the interconnected challenges of sustainable development, it will be necessary to consider using integrated approaches at all levels [23]. This means, achieving sustainable development will require innovation-centered approaches and inter - and trans-disciplinary research [30-31] and other new approaches that have been documented [26]. Nonetheless, it is difficult to realize beneficial outcomes of research and innovation without the requisite platforms or infrastructures, a strong political commitment, and substantial and reliable funding. Investment in research and innovation is therefore fundamental in stimulating the ongoing implementation process of the SDGs. 


\subsection{Research and Innovation - the Sierra Leone Context}

Global investment in research and development is $\$ 2$ trillion [15], mostly occurring in developed and high-income countries. The challenges of embarking on research and innovation in supporting the implementation process of the SDGs, are more acute in the least developed countries and low-income countries where supports and infrastructures are inadequate. Taking Sierra Leone as an example, there is an under-investment in research, albeit innovation is increasingly gaining national attention. Taken as a whole, the national research and innovation output at the moment is low. The underinvestment particularly in research schemes, can extensively impede efforts of internalizing the SDGs within the policies and culture of the universities and research institutions in Sierra Leone. This could consequently limit the ability of researchers and academics to directly address the challenges of implementing and monitoring the SDGs through developing new knowledge, approaches, and tools relevant to the SDGs.

It seems reasonable to speculate that to avoid reproducing the pattern of uneven progress and data disparity that had characterized the MDGs campaign in Sierra Leone, there must be a more explicit recognition of the role of research and innovation in implementing the SDGs. It is essential that policymakers and politicians in Sierra Leone acknowledge that a failure to support and allow space for researchers, academicians and innovators to contribute to the SDGs can lead to absurd results.

\subsection{The Role of Government in Mainstreaming Research and Innovation to Implement the SDGs}

One of the prime features of the sustainable development schema is to provide a common framework for different stakeholders to meet and work collaboratively on shared interests [26]. Unlike the MDGs, measuring progress on the SDGs is not an easy task, taking into account the increased number of goals, targets and indicators and their cross-thematic features. The dedicated partnership between the Government of Sierra Leone, research and educational institutions, in close cooperation with international partners; is a prerequisite to exchange ideas, and roll out innovative ways to harness the synergies and address the problems of the SDGs. This will, however, require a give and take approach, as each sector and stakeholder in the SDGs clusters must first identify and know its roles and responsibilities for achieving the SDGs.

On the side of government, it must take a central leadership role in creating the enabling environment, beginning with a reform of the tertiary education system with the ultimate goal of depoliticizing universities and colleges. The reform should reflect the fact the tertiary education sector is not the relevant platform to institutionalized politics in any form but it is a sector that needs support to drive technological and societal progress through research, discovery and knowledge creation, and adoption [26].

In its National Innovation and Digital Strategy (NIDS), the
Government of Sierra Leone pointed out that it will "support human capital development" as well as "state-of-the-art research advancement" [32]. Therefore, as far as resources are concerned, the government should commit itself to provide sound, predictable, reliable and sustainable financial support by means of setting up a National Research and Innovation Fund (NRIF). Once such fund is operationalized, it will help to support researchers and universities, and innovators through grants and other research projects as it is the case in other countries that are today considered as the epitome of research and innovation. Also, great importance must be attached to the need for building up scientific infrastructures. This will create the requisite platform for professionals to practice and display their knowledge in the most relevant areas of the SDGs. It would provide academia and think tanks with adequate opportunity for executing their roles of not only "analyzing and assessing progress towards the goals, but also acting as knowledge brokers between sectors and stakeholders to enable greater dialogue between the general public, decision-makers and wider society" [5]. Further, the building of research infrastructures can be considered as an appropriate way to bring together professionals at home and abroad, and consequently, bring together a unique suite of perspectives and experiential learning for the SDGs.

Finally, in recognition of the critical linkages between data availability, accessibility and policymaking, there is a need to develop a comprehensive national research and innovation policy. The policy should be 'stand-alone' and should not be integrated into the national education policy of the country. The policy should among other things, seek to create a data linkage between the national statistical system and data obtained by academic and independent researchers and organizations. This is because some data that is useful for decision making can only be obtained or produced by researchers and academics. If there is no explicit recognition of data on Sierra Leone reported in peer-reviewed literature, and in some cases data archives by research organizations, it could pose a challenge of reasonable decision making. For research on the SDGs to yield the desired outcome, the peer-reviewed data must be vividly reflected in the national statistical database. This is an important step in providing an empirical basis necessary for evidence-based decision making and the formulation of policies for sustainability pathways.

\subsection{Tertiary Education Sector and Research Institutions Contribution to the SDGs in Sierra Leone}

The tertiary education and scientific research sectors are explicitly recognized in a number of the SDGs; however, university inputs are much more needed to accomplish the targets contained in all of the SDGs [26]. The general roles of universities to the SDGs have been previously documented $[26 ; 23]$ as those details cannot be discussed here.

The question of how tertiary and research institutions, and innovation platforms, could meaningfully contribute to the SDGs in Sierra Leone is complex, because of the cross-cutting nature of the goals and the organizations and institutions 
involved. This complexity might be an impediment to foster synergistic interaction across disciplines. Therefore, the concept of replacing the tree model of science and research with a web model to develop solutions [33], is thought to provide the best opportunity to address these challenges. This concept applies to all institutions, both large and small. This approach which seeks to expand interdisciplinary collaboration in research and innovation for the SDGs is necessary to ensure researchers, academicians, and innovators do not work in disciplinary silos. This is in recognition of complementary pieces of knowledge and "ecosystem of expertise" required to help build sustainable outcomes [34]. Following this line of reasoning, each institution must first identify the national SDGs objectives for Sierra Leone, and as pointed out by SDSN, [26] align themselves with those objectives that falls within their operational sphere of influence. To intensify collaborations between researchers and innovators alike, it will be necessary to develop a national research agenda, although there is an existing national strategy for innovation.

Even though some research institutions in Sierra Leone are not adequately funded, as a start, basic and applied research can help in addressing real-world problems, societal needs, and mindsets, essential to break new ground of and for sustainability [23]. For the case of universities, it is never too late to start to integrating the SDGs into the academic curriculum and research areas. Student dissertations, thesis, academic research projects among others should be considered as a starting point for illustrating the commitment of conceptualizing, developing and implementing strategies for the SDGs. Also, the Sierra Leone Research and Education Network (SLREN) [35] is another meaningful platform to mainstream the SDGs in the tertiary education system.

\section{Saving the Foundation of Innovation in Sierra Leone}

On 29 October 2018, the Government of Sierra Leone launched what could be best described as the country's first national Directorate of Science Technology and Innovation (DSTI) [36]. The move was a widely-lauded venture and a good starting point for strengthening support for evidence-based actions and initiatives. The DSTI has made commendable progress over the few months since its establishment. Some of these include the creation of an integrated Geographical Information System (iGIS), deployment of blockchain digital ID platform to make financial services among others (See the DSTI website [37]).

In November 2019, the government has also launched the National Digital and Innovation Strategy (NIDS) which will serve as the national vision to digitize the way the government manages its resources and how citizens can access services. It is also been framed as the country's road map towards moving from analog to digital within the next 3 to 10 years [32]. Globally, the implementation of digital government has been going through policies and implementation paradigms.
Oftentimes, "these are tied to waves of ideological trends in public policy and public management" [38]. Indeed, the focus of most digital government initiatives is driven by each administration's national priorities [38]. In the Sierra Leone context, the DSTI was actually established by the current regime but its longevity in successive governments remained a subject of debate given that, the dissolution, creation, merge of government offices (institutions); is one of the prime tenets of the political governance system of Sierra Leone. It is a fact that even the current administration had closed, merged, separated government institutions and in some cases established new ones. In spite of all the positive development strides of the DSTI, it is extremely possible for a future government to reach a decision on the discontinuity of its operation. Should this happen, it could be seen as a reversal in the drive towards promoting innovation in Sierra Leone. It is important to note that "Since 1987, sustainability has become the distinctive feature of any discourse and sustainable development the only possible way to operate in any field" [39]. Therefore, from a policy and sustainable planning perspective, it makes sense that the DSTI should be protected by an act of parliament or any resolution that would provide a wide margin of protection against the intent of a future government that would seek to discontinue its operation. For instance, in the US, there is the U.S. e-Government act, with a focus on providing access to online government services for different stakeholders [40].

However, as it is at the current time, the DSTI must work to embracing different ways of knowing and avoiding a narrow focus on specific skills or thematic focus areas (thematic niches). This is in recognition of: (1) the diversity of innovation for sustainable development as detailed in the review of Silvestre \& îrcă [41], and other new innovative approaches to support the implementation of the SDGs that have been well documented [42] (2) innovative solutions to problems of sustainable development require both specialist and non-specialist knowledge. In fact, it is a common conviction that fostering a culture of innovation would require an inclusive and participatory approach [43] to incorporate the ingenuity of underrepresented groups and minorities. By so doing, this will widen the space for innovation, and spur up local change. As detailed in the national innovation and digital strategy, "the local creative and entrepreneurial economy must be bootstrapped through digitization" [32]. Therefore, it is of great importance that the DSTI work to ensure that indigenous knowledge systems are adequately tapped and utilized to support the acceleration and implementation of the goals in the country. Also, it is important to note that when the creative potential of indigenous people is isolated or not given sufficient focus, there would be gaps which mainstream research and innovation cannot solve alone.

\section{Conclusion}

Unlike the Millennium Development Goals (MDGs), the Sustainable Development Goals (SDGs) are universal in aims and scopes. The adoption and implementation depend on 
national realities and circumstances of every UN Member States. In this paper, we disentangle the need for having a comprehensive national sustainable development plan for Sierra Leone. The support and commitments of all national political parties are key for designing and implementing the SDGs related programs and activities, with periodic review to ensure relevance and effectiveness.

"The SDGs place greater demands on the scientific community than the MDGs because tackling systemic challenges and determinants requires research" that takes social, economic, and environmental dimensions into consideration [5]. Thus, investment in research and innovation would have multiplier positive impacts on the SDGs but the Government of Sierra Leone should establish a national research and innovation fund, have a research and innovation policy, and build the necessary infrastructures to better realize the contribution of the scientific community to the SDGs. On the other hand, universities and research institutions, and innovators should seek an interdisciplinary approach to ensure that key questions and important evidence gaps relating to sustainable development are addressed in a way that is relevant, resource-efficient and sustainable.

\section{References}

[1] United Nations (UN) (2015). Transforming our world: the 2030 Agenda for Sustainable Development. New York: United Nations.

https://sustainabledevelopment.un.org/post2015transformingo urworld (accessed February 10, 2020).

[2] Chams, N., and García-Blandón, J (2019). On the importance of sustainable human resource management for the adoption of sustainable development goals. Resources, Conservation \& Recycling 141, 109-122. https://doi.org/10.1016/j.resconrec.2018.10.006.

[3] Galli, A., Đurović, G., Hanscom, L., and Knežević, J (2018) Think globally, act locally: Implementing the sustainable development goals in Montenegro. Environmental Science and Policy 84, 159-169.

[4] Martin, D. A (2019). Linking fire and the United Nations Sustainable Development Goals. Science of the Total Environment 662, 547-558.

[5] Kickbusch, I., and Hanefeld, J (2017). Role for academic institutions and think tanks in speeding progress on sustainable development goals. BMJ; 358:j3519 doi: 10.1136/bmj.j3519.

[6] Xiao, X., Norris, C. B., Lenzen, M., Norris, G., and Murray, J (2017). How Social Footprints of Nations Can Assist in Achieving the Sustainable Development Goals. Ecological Economics 135, 55-65.

[7] Allen, C., Metternicht, G., and Wiedmann, T (2016) National pathways to the Sustainable Development Goals (SDGs): A comparative review of scenario modelling tools. Environmental Science \& Policy 66, 199-207.

[8] Ottersen O. P., Dasgupta J., Blouin C., et al. (2014). The political origins of health inequality: prospects for change. Lancet; 383: 630-67.
[9] Engebretsen, E., Heggen, K., and Ottersen, O. P (2017). The Sustainable Development Goals: ambiguities of accountability. The Lancet. 389: 365.

[10] United Nations, Department of Economic and Social Affairs (2016). Sustainable Development Knowledge Platform. Voluntary National Reviews Database.

https://sustainabledevelopment.un.org/vnrs/ [accessed December 2019].

[11] Government of Sierra Leone: Ministry of Finance and Economic Development (MoFED) (2016). Sierra Leone: SDGs Adaptation Report http://mofed.gov.sl/PUBLICATIONS/08_07_16FinalDraft_Ne wYork2.pdf [accessed December 2019].

[12] Government of Sierra Leone: Ministry of Planning and Economic Development (July 2019). 2019 VNR report on the SDGs in Sierra Leone.

https://sustainabledevelopment.un.org/content/documents/233 78Sierra_Leone_VNR_FINAL.pdf [accessed December 2019].

[13] United Nations (2018). The Sustainable Development Goals Report 2018.

https://unstats.un.org/sdgs/files/report/2018/TheSustainableDe velopmentGoalsReport2018-EN.pdf [accessed December 2019].

[14] Sachs, J., Schmidt-Traub, G., Kroll, C., Lafortune, G., and Fuller, G. (2018). SDG Index and Dashboards Report 2018. New York: Bertelsmann Stiftung and Sustainable Development Solutions Network (SDSN).

[15] United Nations (2019). The Sustainable Development Goals Report 2019. United Nations, New York.

[16] Bryan, B. A., Hadjikakou, M., and Moallemi, E. A (2019). Rapid SDG progress possible. Nature Sustainability, 2, 999 1000, https://doi.org/10.1038/s41893-019-0422-z.

[17] Government of Sierra Leone: Ministry of Development and Economic planning (2003). Sierra Leone Vision 2025: "Sweet Salone"

https://unipsil.unmissions.org/sites/default/files/vision_2025.p df [accessed February 2020].

[18] Witness To Truth: Report of the Sierra Leone Truth \& Reconciliation Commission, Volume 3B (2004). ISBN 9988-8097-6-X, Graphic Packaging Ltd. GCGL Ghana. http://www.sierra-leone.org/Other-Conflict/TRCVolume3B.pd $\mathrm{f}$ and at www.sierra-leone.org/TRCDocuments.html.

[19] Government of Sierra Leone: Ministry of Finance and Economic Development (2012). The Agenda for Prosperity. Road to Middle income Status. Sierra Leone's Third Generation Poverty Reduction Strategy. www.undp.org/content/dam/.../undp_sle_The $\% 20$ Agenda $\% 20$ for\%20Prosperity\%20.pdf (accessed January 20, 2020).

[20] Government of Sierra Leone: Ministry of Development and Economic Planning (2019). Sierra Leone's Medium-Term National Development Plan 2019-2023. Education for all. Volume $1 . \quad$ Available from: www.moped.gov.sl/wp.../03/Medium-Term-National-Develop ment-Plan-Volume-I.pdf [accessed January 20, 2020].

[21] East, M., and White, R. M (2016). Reflecting on the Emergence of the UN Sustainable Development Goals: A Call for Action in Scotland; Report for Scottish Government and COSLA; Scottish Government and COSLA: St Andrews, UK, p. 55. 
[22] Giangrande, N., White, R, M., East, M., Jackson, R., Clarke, T., Coste, M, S., and Penha-Lopes, G (2019). A Competency Framework to Assess and Activate Education for Sustainable Development: Addressing the UN Sustainable Development Goals 4.7 Challenge. Sustainability, 11, 2832.

[23] Körfgen, A., Förster, K., Glatz, I., Maier, S., Becsi, B., Meyer, A., Kromp-Kolb, H., and Stötter, J (2018). It's a Hit! Mapping Austrian Research Contributions to the Sustainable Development Goals. Sustainability, 10, 3295; doi: $10.3390 /$ su10093295.

[24] El-Jardali, F., Ataya, N., and Fadlallah, R (2018). Changing roles of universities in the era of SDGs: rising up to the global challenge through institutionalising partnerships with governments and communities. Health Res Policy Syst. 16: 38 Doi: 10.1186/s12961-018-0318-9.

[25] Brolan, C. E., Lee, S., Kim, D., and Hill, P. S., (2014). Back to the future: what would the post-2015 global development goals look like if we replicated methods used to construct the Millennium Development Goals? Global. Health 10, 19. doi: 10.1186/1744-8603-10-19.

[26] Sustainable Development Solutions Network, Australia/Pacific (2017). Getting started with the SDGs in universities: A guide for universities, higher education institutions, and the academic sector. Australia, New Zealand and Pacific Edition. Sustainable Development Solutions Network - Australia/Pacific, Melbourne.

[27] Lehoux, P., Silva, H. P., Sabio, R. P., and Roncarolo, F (2018). The Unexplored Contribution of Responsible Innovation in Health to Sustainable Development Goals. Sustainability, 10, 4015; doi: 10.3390/su10114015.

[28] Schmalzbauer B., and Visbeck M (Eds.) (2016). The contribution of science in implementing the Sustainable Development Goals. German Committee Future Earth, Stuttgart/Kiel.

[29] Global University Network for Innovation (GUNi) (2018). Sustainable Development Goals: Actors and Implementation A Report from the International Conference. First edition, Barcelona, May 2018.

[30] Leal Filho, W., Ulisses, A., Alves, F., Pace, P., Mifsud, M., Brandli, L., Caeiro, S. S., and Disterheft, A (2018): Reinvigorating the sustainable development research agenda: the role of the sustainable development goals (SDG), Int. J. Sustain. Dev. World Ecol 25 (2), 131-142 DOI: 10.1080/13504509.2017.1342103.

[31] Silvestre, B. S (2015). A hard nut to crack! Implementing supply chain sustainability in an emerging economy. J. Clean. Prod. 96, 171-181
[32] Directorate of Science and Technology (2019). Sierra Leone National Innovation and Digital Strategy (2019-2029) https://www.dsti.gov.sl/wp-content/uploads/2019/11/Sierra-Le one-National-Innovation-and-Digital-Strategy.pdf.

[33] Liu, J., Bawa, K. S., Seager, T. P., Mao, G., Ding, D., Lee, J. S. H., and Swim, J. K (2019) On knowledge generation and use for sustainability. Nature Sustainability, 2, 80-82.

[34] Brand, R., and Karnoven, A. (2007) The ecosystem of expertise: Complementary knowledges for sustainable development. Sustain. Sci. Pract. Policy, 3, 21-31.

[35] Sierra Leone Research and Education Network (SLREN) https://slren.edu.sl/node/1 [accessed March 2020].

[36] State House Media and Communications Unit (2018) President Julius Maada Bio Unveils Sierra Leone's First Directorate of Science, Technology and Innovation. https://statehouse.gov.sl/president-julius-maada-bio-unveils-si erra-leones-first-directorate-of-science-technology-and-innova tion/ [accessed November 2019].

[37] Directorate of Science, Technology and Innovation https://www.dsti.gov.sl/ [accessed November 2019].

[38] Mergel, I (2019). Digital service teams in government. Government Information Quarterly 36, 101389. https://doi.org/10.1016/j.giq.2019.07.001.

[39] Conte, E (2018). The Era of Sustainability: Promises, Pitfalls and Prospects for Sustainable Buildings and the Built Environment. Sustainability, 10, 2092; doi: $10.3390 /$ su10062092.

[40] U. S. Congress (2002). E-government act of 2002 - title II Federal Management and promotion of electronic government services. Pub. L. 107-347, 116 stat. 2899, 44 U.S.C. $\$ 101$, H. R. 2458/S. 803. Washington, DC: 44th U.S. Congress.

[41] Silvestre, B. S., and îrcă, D. M (2019). Innovations for sustainable development: Moving toward a sustainable future. Journal of Cleaner Production 208, 325-332. https://doi.org/10.1016/j.jclepro.2018.09.244.

[42] United Nations Conference on Trade and Development (UNCTAD/DTL, STICT/2017/4. New innovation approaches to support the implementation of the Sustainable Development Goals. Available from https://unctad.org/en/PublicationsLibrary/dtlstict2017d4_en.p df [accessed March 2020].

[43] Editorial (2019). Round four on the environment. Nature Sustainability, 2,157. 